\title{
Correction to: Body Dysmorphic and Narcissistic Personality Disorder in Cosmetic Rhinoplasty Candidates
}

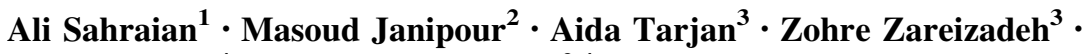 \\ Pardis Habibi ${ }^{4} \cdot$ Amirhossein Babaei $^{2,4}$
}

Published online: 20 December 2021

(C) Springer Science+Business Media, LLC, part of Springer Nature and International Society of Aesthetic Plastic Surgery 2021

\section{Correction to: Aesth Plast Surg https://doi.org/10.} 1007/s00266-021-02603-x

This article was updated to correct errors in Tables 1 and 3 and the acknowledgements.
Publisher's Note Springer Nature remains neutral with regard to jurisdictional claims in published maps and institutional affiliations.

The original article can be found online at https://doi.org/10.1007/ s00266-021-02603-x.

Masoud Janipour

masood.janipoor@gmail.com

1 Research Center for Psychiatry and Behavioural Sciences, Shiraz University of Medical Sciences, Shiraz, Iran

2 Otolaryngology Research Center, Department of Otolaryngology, Shiraz University of Medical Sciences, Shiraz, Iran

3 Department of Psychiatry, Shiraz University of Medical Sciences, Shiraz, Iran

4 Student research committee, Shiraz University of Medical Sciences, Shiraz, Iran 